\title{
CRISPR/Cas9 knockout of EPFL10 reduces stomatal density while maintaining photosynthesis and enhancing water conservation in rice
}

Nicholas G. Karavolias, Dhruv Patel, Kyungyong Seong, Michelle Tjahjadi, GloriaAlexandra Gueorguieva, Jaclyn Tanaka, Douglas Dahlbeck, Myeong-Je Cho, Krishna K. Niyogi, Brian J. Staskawicz

\section{Summary}

Rice production is of paramount importance for global nutrition and potential yields will be detrimentally affected by climate change. Rice stomatal developmental genetics were explored as a mechanism to improve water use efficiency while maintaining yield under climate stress.

Gene-editing of STOMAGEN and its paralog, EPFL10, using CRISPR/Cas9 in rice cv. Nipponbare yielded lines with altered stomatal densities that were functionally characterized. CRISPR/Cas9 mediated knockouts of EPFL10 and STOMAGEN yielded lines with c. $80 \%$ and $25 \%$ of wild-type stomata, respectively.

epfl10 lines with small reductions in stomatal densities are able to conserve water to similar extents as stomagen lines with large stomatal density reductions but do not suffer from any concomitant reductions in stomatal conductance, carbon assimilation, or thermoregulation.

The duplicate of STOMAGEN, EPFL10, is a weak positive regulator of stomatal development in rice. epfl10 lines maintained wild-type physiological characteristics while conserving more water. Modest reductions in stomatal densities may be a climate-adaptive approach in rice that can safeguard yield.

\section{Introduction}

The need to develop climate change adapted crops in the face of rapid global population increases and worsening climates is necessary and timely. Prolonged periods of drought and increased desertification are anticipated to become more prevalent in the next century (IPCC et al., 2021). Climate change modeling predicts increases in global temperatures by $2-4{ }^{\circ} \mathrm{C}$ by the end of the $21^{\text {st }}$ century. Increased temperatures alone and in combination with limited water will negatively impact crop yields (Jagadish, Murty, \& Quick, 2015; Rang, Jagadish, Zhou, Craufurd, \& Heuer, 2011; Shah et al., 2011). Rice (Oryza sativa) is the most widely directly consumed crop globally and trails only wheat and maize in area harvested (Food and Agriculture Organisation (FAO), 2020). Originally domesticated in semi-aquatic habitats, rice is especially sensitive to drought relative to other C3 cereal crops (Bernier, Atlin, Serraj, Kumar, \& Spaner,

44 2008; Jägermeyr et al., 2021; Lafitte, Ismail, \& Bennett, 2004). 
Future water limitations may necessitate transitions of fully flooded paddy conditions to watersaving production schemes (Jagadish et al., 2015). Rain-fed production, which comprises about $45 \%$ of total rice grown, is particularly susceptible to drought as a result of unpredictable precipitation (Khush, 1997; Pandey et al., 2007; Tuong \& Bouman, 2009). Furthermore, most regions where irrigated rice is produced are currently experiencing or are projected to experience water scarcity (Tuong \& Bouman, 2009). Thus, all rice, regardless of production method, would benefit from improvements that maintain yields with lower water requirements. $90 \%$ of water loss in rice occurs via transpiration from the stomata necessitating explorations of stomata-driven improvements in water conservation (T. N. Buckley, 2005).

Stomata are at the nexus of plants and the atmosphere. They facilitate gaseous exchanges of carbon dioxide, oxygen, and water vapor. The development of these essential structures has been studied extensively in model systems with growing understandings of development in non-model plant as well (Endo \& Torii, 2019; Liu, Ohashi-Ito, \& Bergmann, 2009; Tiago D.G. Nunens, Dan Zhang, 2019) . Grass stomata are morphologically distinct from classically studied Arabidopsis thaliana stomata, possessing physiologically linked subsidiary cells flanking dumbbell-shaped guard cells among other unique features (Stebbins \& Shah, 1960; Tiago D.G. Nunens, Dan Zhang, 2019). Furthermore, grass stomata mature basipetally along the longitudinal axis of leaves and are distributed in files adjacent to vasculature unlike the stomata of Arabidopsis thaliana (Tiago D.G. Nunens, Dan Zhang, 2019). In parallel with their divergent structure, the grass stomatal developmental framework contains variations from well-studied eudicot regulatory pathways which account for some of the observed phenotypic variation. For example, the Brachypodium distachyon ortholog of the conserved transcription factor MUTE has evolved a novel role in specifying subsidiary cell identity through acquisition of cell-to-cell mobility (Raissig et al., 2017).

Despite these differences, the core regulatory wiring of stomatal development is largely conserved in angiosperms (Liu et al., 2009). Epidermal patterning factors (EPF) are essential to the regulation of stomatal development. EPFs in the context of stomatal development, are mobile peptides that regulate cell fate transitions and cell divisions to ensure proper spacing and number of stomata (Hara, Kajita, Torii, Bergmann, \& Kakimoto, 2007; Hara et al., 2009; Hunt \& Gray, 2009; Shimada, Sugano, \& Hara-Nishimura, 2011). These peptides are cysteine rich with conserved cysteine residues near the C-terminal end. EPF1 and EPF2 function as negative regulators. EPF2 in Arabidopsis thaliana is known to act before EPF1 to inhibit entry into the stomatal lineage by limiting asymmetric divisions (Hara et al., 2009; Hunt \& Gray, 2009). EPF1 regulates the differentiation of guard mother cells in Arabidopsis thaliana.(Hara et al., 2007).

Unlike EPF1 and EPF2 which serve as negative regulators, EPF-LIKE9, or STOMAGEN, is a positive regulator of stomatal development in Arabidopsis thaliana and O. sativa (Hunt, Bailey, \& Gray, 2010; Sugano et al., 2010a; Yin et al., 2017) EPF1 and EPF2 are expressed in the stomatal lineage cells, whereas EPFL9 is mesophyll derived (Hara et al., 2007, 2009; Hunt \& Gray, 2009; Shimada et al., 2011). EPFL9 is composed of three distinct regions: an N-terminal signal peptide region, a pro-peptide region, and a $\mathrm{C}$-terminal cysteine-rich active peptide region (Ohki, Takeuchi, \& Mori, 2011; Sugano et al., 2010a). The full-length peptide is processed invivo to yield a 45 C-terminal amino acid active peptide (Lee et al., 2015; Sugano et al., 2010a) . The active peptide encoded by EPFL9 possesses the conserved cysteine residues of other EPF1 
and EPF2 and binds the same ERECTA (ER)-family receptors and co-receptor TOO MANY MOUTHS (TMM) in Arabaidopsis thaliana (Hepworth, Caine, Harrison, Sloan, \& Gray, 2018; Lee et al., 2015; Shimada et al., 2011; Sugano et al., 2010b).

EPF2 and EPFL9 competitively bind to the ERECTA (ER)-family and co-receptor TOO MANY MOUTHES (TMM) to mediate downstream effects (Lee et al., 2015). Binding of EPFL9 to the TMM/ER complex prevents inhibition of stomatal development in Arabidopsis thaliana. (Lee et al., 2015) STOMAGEN knockdown using RNAi in A. thaliana reduces stomatal densities to $40 \%$ of wild type (Sugano et al., 2010a). Likewise, a knockout of EPFL9 in rice using CRISPR/Cas9 and CRISPR/Cpf1 yielded an eightfold reduction in abaxial stomatal density in the IR64 background (Yin et al., 2017).

Interestingly, EPFL9 has undergone a duplication event in Poaceae leading to multiple copies in all species surveyed (Hepworth et al., 2018). Overexpression of rice STOMAGEN and its duplicate, previously named EPFL9-2, in A. thaliana revealed a common, though reduced, function of EPFL9-2 as a positive regulator of stomatal development when ectopically expressed (Lu et al., 2019). Ectopic expression of Brachypodium distachyon and Triticum aestivum STOMAGEN and STOMAGEN paralogs in Arabidopsis thaliana resulted in similar stomatal density increases (Jangra et al., 2021). In contrast, overexpression of negative regulators of stomatal development reduced stomatal density and improved water use efficiency in Arabidopsis thaliana, wheat, barley, and rice. (Caine et al., 2019; Dunn et al., 2019; Franks, W. Doheny-Adams, Britton-Harper, \& Gray, 2015; Hepworth, Doheny-Adams, Hunt, Cameron, \& Gray, 2015; Hughes et al., 2017; Mohammed et al., 2019). However, all stomatal density reductions achieved by overexpressing negative regulators of stomatal development to any extent also reduced stomatal conductance and carbon assimilation under physiologically relevant light conditions (Caine et al., 2019; Dunn et al., 2019; Hughes et al., 2017). For example, rice lines overexpressing EPF1 to reduce stomatal densities, exhibited lower stomatal conductance and carbon assimilation at all light conditions that exceeded $1000 \mu \mathrm{mol}$ photos $\mathrm{m}^{-2} \mathrm{~s}^{-1}$ (Caine et al., 2019).

115 Stomatal conductance is essential for crop productivity (Fischer et al., 1998; Kusumi, Hashimura, Yamamoto, Negi, \& Iba, 2017; Ohsumi, Kanemura, Homma, Horie, \& Shiraiwa, 2007a; Richards, 2000; Roche, 2015; Taylaran, Adachi, Ookawa, Usuda, \& Hirasawa, 2011; Zhang et al., 2021). In rice specifically, higher stomatal conductance has been associated with greater rates of leaf photosynthesis (Kusumi et al., 2017; Ohsumi, Kanemura, Homma, Horie, \& Shiraiwa, 2007b; Zhang et al., 2021). Efforts to enhance stomatal conductance have led to increased leaf photosynthesis and biomass accumulation in a range of C3 plants (Kusumi et al., 2017; Papanatsiou et al., 2019; Wang et al., 2014; Zhang et al., 2021). Thus, opportunity exists to further fine-tune stomatal density reductions to maintain wild-type levels of carbon assimilation and stomatal conductance while enhancing water conservation and drought resilience. referred to as EPFL10, in its relationship to stomatal development. Furthermore, we explore the effect of the reductions in stomatal density in stomagen and epfl10 mutants on stomatal

128 conductance, carbon assimilation, water conservation, and yield in varying water regimes. 


\section{Methods}

Plant Growth conditions:

131 Rice cultivar Nipponbare (Oryza sativa ssp. Japonica) seeds were germinated and grown for 132 eight days in a petri dish with $20 \mathrm{~mL}$ of water in a Conviron growth chamber at $28^{\circ} \mathrm{C}$ for day133 length periods of 16 hours in $100 \mu \mathrm{mol}$ photons $\mathrm{m}^{-2} \mathrm{~s}^{-1}$ of light and $80 \%$ relative humidity.

134 Seedlings were transferred to a soil mixture comprised of equal parts turface

135 (https://www.turface.com/products/infield-conditioners/mvp) and sunshine mix \#4

136 (http://www.sungro.com/professional-products/fafard/).

137 Germinated seedlings used for stomatal phenotyping and growth chamber physiological assays 138 were transferred to $10.16 \mathrm{~cm}, 0.75 \mathrm{~L} \mathrm{McConkey} \mathrm{tech} \mathrm{square} \mathrm{pots} \mathrm{and} \mathrm{placed} \mathrm{in} \mathrm{growth} \mathrm{chambers}$ $13928^{\circ} \mathrm{C}$ for day-length periods of 16 hours in $400 \mu \mathrm{mol}$ photons $\mathrm{m}^{-2} \mathrm{~s}^{-1}$ of light and $80 \%$ relative 140 humidity.

141 Plants designated for yield trials, greenhouse physiological assays, and stomatal aperture 142 measurements were moved to the greenhouse with temperature setpoints of $27^{\circ} \mathrm{C} / 22^{\circ} \mathrm{C}$ at 143 ambient light conditions in February 2020 with daylengths of $12 \mathrm{~h}$ in Kord $15.24 \mathrm{~cm}, 1.835 \mathrm{~L}$ 144 pots.

145 All plants were fertilized with $125 \mathrm{~mL}$ of $1 \% \mathrm{w} / \mathrm{v}$ iron solution one-week post-transplant.

$1461000 \mathrm{~mL}$ of 5\% w/v JR Peter's Blue 20-20-20 fertilizer (https://www.jrpeters.com/) was added to 147 each flat at 3- and 11-weeks post-germination. Well-watered plants were provided a constant 148 supply of water by maintaining a flooded condition in the tray.

\section{Yield and water regimes:}

150 Yield in three watering regimes were tested: well-watered, vegetative drought, and reproductive 151 drought. Yield trials in varying water regimes were conducted using methods adapted and 152 modified slightly from Caine et. al 2019. Well-watered flats were kept flooded for the entirety of 153 the growth period. Vegetative drought was imposed by removing all water from flats containing 154 pots for 7 days starting on day 28 after germination and for 9 days at day 56 after germination. In 155 reproductive drought, water was removed from flats for 4 days at day 98 when panicles were 156 undergoing grain filling. All grain and aboveground biomass from well-watered, vegetative and 157 reproductive drought plants were harvested after 167 days, 177 days, and 181 days, respectively. 158 Biomass measurements were completed on samples dried at $60^{\circ} \mathrm{C}$ for three days prior to 159 weighing.

161 Generation of edited lines:

162 Guides for targeting EPFL10 and STOMAGEN were selected to minimize off-targets effects and 163 maximize on-target efficiency in the first exon of the coding region. Guide sequences were 164 selected using CRISPR-P 2.0 (http://crispr.hzau.edu.cn/CRISPR2/). Forward and reverse strand 
guide sequence oligonucleotides with relevant sticky ends amenable for Golden Gate cloning were ordered from IDT (IDTdna.com). Equal volumes of 10mM primers were annealed at room temperature. Golden Gate cloning was used to insert guides into the PeGM entry clone containing the tracrRNA and U3 promoter. LR clonase reactions were used to insert entry clone into destination vectors for biolistic transformation and Agrobacterium-mediated transformation. Plasmid maps are provided in the supporting information. epfl10 lines were produced via Agrobacterium-mediated transformation and stomagen lines via biolistic transformation.

\section{Plant material and culture of explants}

173 Mature seeds of rice (Oryza sativa L. japonica cv. Nipponbare) were de-hulled, and surface174 sterilized for $20 \mathrm{~min}$ in $20 \%$ (v/v) commercial bleach (5.25\% sodium hypochlorite) plus a drop of Tween 20. Three washes in sterile water were used to remove residual bleach from seeds. Dehulled seeds were placed on callus induction medium (CIM) medium [N6 salts and vitamins (Chu et al., 1975), $30 \mathrm{~g} / \mathrm{L}$ maltose, $0.1 \mathrm{~g} / \mathrm{L}$ myo-inositol, $0.3 \mathrm{~g} / \mathrm{L}$ casein enzymatic hydrolysate, $0.5 \mathrm{~g} / \mathrm{L}$ L-proline, $0.5 \mathrm{~g} / \mathrm{L}$ L-glutamine, $2.5 \mathrm{mg} / \mathrm{L} \mathrm{2,4-D,} 0.2 \mathrm{mg} / \mathrm{L}$ BAP, $5 \mathrm{mM} \mathrm{CuSO}$, $3.5 \mathrm{~g} / \mathrm{L}$ Phytagel, pH 5.8] and incubated in the dark at $28{ }^{\circ} \mathrm{C}$ to initiate callus induction. Six- to 8-weekold embryogenic calli were used as targets for transformation.

Agrobacterium-mediated transformation EHA105 suspension $\left(\mathrm{OD}_{600 \mathrm{~nm}}=0.1\right)$ carrying a binary vector of interest, OsEPFL10. After a 30 min incubation, the Agrobacterium suspension was removed. Calli were then placed on sterile filter paper, transferred to co-cultivation medium [N6 salts and vitamins, $30 \mathrm{~g} / \mathrm{L}$ maltose, $10 \mathrm{~g} / \mathrm{L}$ glucose, $0.1 \mathrm{~g} / \mathrm{L}$ myo-inositol, $0.3 \mathrm{~g} / \mathrm{L}$ casein enzymatic hydrolysate, $0.5 \mathrm{~g} / \mathrm{L}$ L-proline, $0.5 \mathrm{~g} / \mathrm{L}$ L-glutamine, $2 \mathrm{mg} / \mathrm{L} \mathrm{2,4-D,} 0.5 \mathrm{mg} / \mathrm{L}$ thiamine, $100 \mathrm{mM}$ acetosyringone, $3.5 \mathrm{~g} / \mathrm{L}$ Phytagel, $\mathrm{pH}$ 5.2] and incubated in the dark at $21^{\circ} \mathrm{C}$ for 3 days. After co-cultivation, calli were transferred to resting medium [N6 salts and vitamins, $30 \mathrm{~g} / \mathrm{L}$ maltose, $0.1 \mathrm{~g} / \mathrm{L}$ myo-inositol, $0.3 \mathrm{~g} / \mathrm{L}$ casein enzymatic hydrolysate, $0.5 \mathrm{~g} / \mathrm{L}$ L-proline, $0.5 \mathrm{~g} / \mathrm{L}$ L-glutamine, $2 \mathrm{mg} / \mathrm{L} \mathrm{2,4-D,} 0.5 \mathrm{mg} / \mathrm{L}$ thiamine, $100 \mathrm{mg} / \mathrm{L}$ timentin, $3.5 \mathrm{~g} / \mathrm{L}$ Phytagel, pH 5.8] and incubated in the dark at $28^{\circ} \mathrm{C}$ for 7 days. Calli were then transferred to selection medium (CIM plus $250 \mathrm{mg} / \mathrm{L}$ cefotaxime and 50 $\mathrm{mg} / \mathrm{L}$ hygromycin B) and allowed to proliferate in the dark at $28^{\circ} \mathrm{C}$ for 14 days. Wellproliferating tissues were transferred to CIM containing $75 \mathrm{mg} / \mathrm{l}$ hygromycin $\mathrm{B}$. The remaining tissues were subcultured at 3- to 4- week intervals on fresh selection medium. When a sufficient amount (about $1.5 \mathrm{~cm}$ in diameter) of the putatively transformed tissues was obtained, they were transferred to regeneration medium [MS salts and vitamins (Murashige \& Skoog, 1962), $30 \mathrm{~g} / \mathrm{L}$ sucrose, $30 \mathrm{~g} / \mathrm{L}$ sorbitol, $0.5 \mathrm{mg} / \mathrm{L}$ NAA, $1 \mathrm{mg} / \mathrm{L}$ BAP, $150 \mathrm{mg} / \mathrm{L}$ cefotaxime) containing 40 $\mathrm{mg} / \mathrm{L}$ hygromycin $\mathrm{B}$ and incubated at $26^{\circ} \mathrm{C}, 16-\mathrm{hr}$ light, $90 \mu \mathrm{mol}$ photons $\mathrm{m}^{-2} \mathrm{~s}^{-1}$. When regenerated plantlets reached at least $1 \mathrm{~cm}$ in height, they were transferred to rooting medium (MS salts and vitamins, $20 \mathrm{~g} / \mathrm{L}$ sucrose, $1 \mathrm{~g} / \mathrm{L}$ myo-inositol, $150 \mathrm{mg} / \mathrm{L}$ cefotaxime) containing 20 $\mathrm{mg} / \mathrm{L}$ hygromycin $\mathrm{B}$ and incubated at $26^{\circ} \mathrm{C}$ under conditions of $16-\mathrm{hr}$ light $(150 \mu \mathrm{mol}$ photons $\mathrm{m}^{-2} \mathrm{~s}^{-1}$ ) and 8-h dark until roots were established and leaves touched the Phytatray lid. Plantlets were then transferred to soil.

\section{Biolistic-mediated transformation}


Embryogenic callus tissue pieces (3-4 mm) were transferred for osmotic pretreatment to CIM medium containing mannitol and sorbitol (0.2 M each). Four hours after treatment with osmoticum, tissues were bombarded as previously described (Cho et al., 2004) with modifications. $7.5 \mathrm{ml}$ of gold particles $(0.6 \mu \mathrm{m})$, coated with $5 \mathrm{mg}$ of pU3Stomagen0.4:OsUbiCas9:HPT were divided equally among 10 macro-carriers and used for bombardment with a Bio-Rad PDS-1000 He biolistic device (Bio-Rad, Hercules, Calif.) at 650 psi. Sixteen to $18 \mathrm{hr}$ after bombardment, tissues were placed on osmotic-free CIM and incubated at $28^{\circ} \mathrm{C}$ under dim light $\left(10-30 \mu \mathrm{mol}\right.$ photons $\mathrm{m}^{-2} \mathrm{~s}^{-1}$, 16-hr light). After 7 days, tissues were transferred to selection medium (CIM containing $50 \mathrm{mg} / \mathrm{l}$ hygromycin B) and maintained/grown using the same procedure as described above, but timentin or cefotaxime were not supplemented in the media.

\section{$217 \quad$ Validation of edits}

$\mathrm{T}_{0}$ plants genotypes at targeted loci were evaluated using PCR to amplify the region of interest using primers listed in Supporting Table 3. PCR products were Sanger sequenced. Sequence data was analyzed using the Synthego ICE tool (https://ice.synthego.com/\#/) to detect alleles present. Only lines with homozygous frame-shift mutations were retained for downstream experiments. Plants from the second generation after transformation were used for experimental data collection generation to account for somaclonal variation, which may have accumulated during tissue culture (Bairu, Aremu, \& Van Staden, 2010; Wei et al., 2016)

Phenotyping stomatal density, size, and aperture:

Stomatal densities were recorded from epidermal impressions of leaves using nail polish peels. Stomatal densities of eight biological replicates of each leaf were measured. Impressions were taken from the widest section of fully expanded leaves. Images were taken using a Leica DM5000 B epifluorescent microscope at 10x magnification. Number of stomata in a single stomatal band were counted and the area of each band was measured (Huang et al., 2019) Stomatal densities were calculated by dividing stomatal counts by stomal band area $\left(\mathrm{mm}^{2}\right)$.

Epidermal peels of 21-day old plants were produced using a razorblade on the adaxial leaf to remove tissues above the abaxial epidermal layer. Images of individual stomata at $100 \mathrm{x}$ magnification were captured. Guard cell length was measured using ImageJ. 35 individual stomata from five biological replicates of each genotype were measured.

Stomatal aperture measurements were generated using epidermal peels of flag leaves from 85day old plants. Leaves were harvested at 1:00pm and peels were generated immediately. Epidermal peels were then fixed by submerging in $4 \%$ formaldehyde for 30 s using a method adapted by Eisele et al. (Eisele, Fäßler, Bürgel, \& Chaban, 2016). Images of 20 individual stomata from six biological replicates of each genotype were measured.

\section{Quantifying EPFL10 and STOMAGEN transcript abundance:}

242 Total RNA was extracted from seedlings eight days after germination, from leaf base and fully

243 expanded leaf of 21-day-old leaves using the Qiagen Total RNAeasy Plant Kit. RNA quality was 
validated on an agarose gel prior to reverse transcription using the QuantiTect ${ }^{\mathrm{TM}}$ reverse transcription kit to generate first-strand cDNA. Quantitative reverse transcription PCR was performed using FAST SYBR on Applied Biosystem's QuantStudio 3 thermocycler. Relative expression levels were calculated by normalizing to the rice UBQ5 housekeeping gene (LOC_Os01g22490) (Jain, Vergish, \& Khurana, 2018). Primers used for qPCR listed in Supporting Table 3. Relative log fold expression was calculated using the $2^{-\triangle \Delta C T}$ method using STOMAGEN in adult leaves as the control group.

\section{Determining methylation profile of genes of interest:}

Methylation profiles of rice genes of interest were viewed using the Plant Methylation Database, (https://epigenome.genetics.uga.edu/PlantMethylome/) (Niederhuth et al., 2016). Snapshots of $\mathrm{CHH}$ and $\mathrm{CHG}$ methylation $1.5 \mathrm{~kb}$ upstream of the start codon and 1.5 downstream of the stop codon were taken.

\section{Evolutionary analysis:}

We collected complete single orthologs from the species used in this study (Table S1), using BUSCO v4.0.6 (Seppey, Manni, \& Zdobnov, 2019) and the viridiplantae_odb10 database. 82 orthologous groups present in at least 23 species were individually selected with MAFFT v7.487 (--maxiterate 1000 --globalpair) (Katoh \& Standley, 2013). All multiple sequence alignments were concatenated, trimmed with TrimAl v1.4.rev15 (-gt 0.2)(Capella-Gutiérrez, Silla-Martínez, \& Gabaldón, 2009) and then used to infer a species tree with FastTree v2.1.10 (Price, Dehal, \& Arkin, 2010). We determined the copy number variations of the STOMAGEN family by searching for the stomagen domain (PF16851) from the protein annotation sets with hmmsearch v3.3 (Eddy, 2011; Mistry et al., 2021) or from the genomes with exonerate v2.2.0 (Slater \& Birney, 2005) if genome annotations are absent. To understand the sequence variations of STOMAGEN and EPFL10 orthologs at the species and family level, we collected non-redundant Oryza or Poaceae species that have single copies of STOMAGEN or EPFL10 (Table S2). The stomagen domain of STOMAGEN or EPFL10 orthologs was aligned with MAFFT, and we used the filtered alignment to compute normalized Shannon's entropy, $-\sum_{i=1}^{20} p_{i} \log _{2} p_{i} / \log _{2} 20$ where $p_{i}$ is the probability of observing $\mathrm{i}^{\text {th }}$ amino acids among the twenty in the given position of the alignment. Gaps were ignored.

\section{Photosynthesis and stomatal conductance assays:}

Physiological assays in Figures 3a, 3c were conducted on full expanded leaf 5 of 21-day old plants. Stomatal conductance and $\mathrm{CO}_{2}$ assimilation data for Fig $3 \mathrm{c}$ was captured using an infrared gas analyzer (LI6400XT, LI-COR, Lincoln, NE, USA) with chamber conditions set to: light intensity $1000 \mu \mathrm{mol}$ photons $\mathrm{m}^{-2} \mathrm{~s}^{-1}$ (90\% red light, $10 \%$ blue light); leaf temperature $27^{\circ} \mathrm{C}$; flow rate $500 \mu \mathrm{mol} \mathrm{s}{ }^{-1}$; relative humidity $40 \%$; and $\mathrm{CO}_{2}$ concentration of sample $400 \mu \mathrm{mol} \mathrm{mol}^{-1}$.

Light response curves in Figure $3 \mathrm{~b}$ and $3 \mathrm{~d}$ were generated using a LI6800 infrared gas analyzer (LI-COR, Lincoln, NE, USA) with chamber conditions set to: leaf temperature $25^{\circ} \mathrm{C}$; flow rate 
$500 \mu \mathrm{mol} \mathrm{s}^{-1}$; water vapor pressure deficit $1.8 \mathrm{kPA}$; and $\mathrm{CO}_{2}$ concentration of sample $400 \mu \mathrm{mol}$ $\mathrm{mol}^{-1}$. Light intensity was first increased to $2000 \mu \mathrm{mol}$ photons $\mathrm{m}^{-2} \mathrm{~s}^{-1}$, and with steady-state waiting times of 5 to 10 minutes, subsequently decreased to $1500,12000,1000,750,500,300$, 200, 100, and $50 \mu \mathrm{mol}$ photons $\mathrm{m}^{-2} \mathrm{~s}^{-1}$ light. Light was composed of at least $90 \%$ red light and at maximum $40 \mu \mathrm{mol}$ photons $\mathrm{m}^{-2} \mathrm{~s}^{-1}$ blue light to match equipment specifications. Measurements were taken on fully expanded fifth leaves of 32-day-old plants grown in the greenhouse. Measurements for Figure S1 were taken on full expanded leaf 5 of 28-day-old plants grown in well-watered and vegetative drought conditions. All data collected were adjusted according to leaf area within the gas exchange chamber. Intrinsic water use efficiency (iWUE) in Figure S3 was calculated by dividing photosynthesis by stomatal conductance for each biological replicate. Specific stomatal conductance in Fig $3 \mathrm{f}$ was calculated by dividing stomatal conductance by the average number of stomata within the probe area.

\section{Thermal imaging:}

Thermal images were captured using a FLIR E8-XT Infrared Camera (FLIR-DIRECT, Wilmington, NC, USA). Images of well-watered and vegetative drought plants were taken 65 days after germination on the last day of the vegetative drought treatment. Images of reproductive drought plants were captured 102 days post-germination on the last day of the reproductive drought treatment. Images were captured between 1:00pm and 2:00pm to capture the effects of transpiration-mediated cooling during the hottest part of the days. Images were processed using FLIR Thermal Studio. Leaf temperatures of 4-6 leaves per biological replicate were quantified.

\section{Water loss}

Two plants of identical genotype were placed in a 10"x10" flat covered with aluminum foil to decrease evaporation from soil. Non-plant evaporation was estimated by measuring daily water loss from covered flats containing pots without plants. Daily water loss of each flat was calculated by taking the difference of flats with plants and without. Eight replicate flats for each genotype were measured daily from 70-77 days after germination.

\section{Graphs and statistics:}

310 All graphs were produced using the ggplot2 package in R studio (Wickham, 2017). All statistics

311 were calculated in R-studio using post-hoc tests for significance between groups.

\section{Results}

\section{Duplication of STOMAGEN in multiple plant families}

315 The duplication of STOMAGEN(EPFL9;LOC_Os01g68598) in the Poaceae family was

316 previously reported (Hepworth et al., 2018) and is in agreement with our expanded gene tree in 317 eudicots and monocots (Fig. 1a). Further resolution of the gene tree suggested that the orthologs 
of STOMAGEN and its duplicate, EPFL10 (LOC_Os08g41360 hereafter referred to as EPFL10), may have evolved differently, given the branch lengths of the two orthologous groups (Fig. 1b). Furhter phylogenetic investigation of the duplication of STOMAGEN among angiosperms revealed an additional putative family-level STOMAGEN duplication in the Asteraceae (Fig. $1 c)$.

\section{Peptide variation between STOMAGEN and EPFL10}

Comparisons of the active 45 amino acid C-terminal sequences of STOMAGEN and EPFL10 indicated that some sequence divergence exists. (Fig. 1d). Sequence conservation of STOMAGEN orthologs is much greater at the genus and family level relative to EPFL10 orthologs. Paralogous sequence variation of STOMAGEN and EPFL10 mapped onto the TMM/ERL1, EPF1 complex highlighted the orientation of dissimilar and similar substitutions within the peptide-receptor complex (Fig. 1e). The two dissimilar amino acids present in the random coil in the beginning of the STOMAGEN domain are near the interface with TMM and ERL1. The substitutions concentrated on the first beta sheet were all mapped to the residues near ERL1, potentially altering binding capacities to the receptor.

\section{Varied expression of EPFL10 and STOMAGEN}

STOMAGEN mRNA abundance greatly exceeds EPFL10 expression in leaf base tissues where stomatal development occurs and STOMAGEN and EPFL10 expression is greatest (Fig. 2a).

\section{Stomatal density and morphology in knockout lines}

CRISPR/Cas9-mediated knockout of STOMAGEN and EPFL10 was achieved by targeting guides to the first exon of each gene to disrupt the open reading frame. Two unique homozygous knockout alleles were generated in EPFL10 and in STOMAGEN in the $\mathrm{T}_{0}$ generation using a single guide sequence adjacent to a PAM motif (designated in green and purple, respectively in Fig. 2b-c). epfl10 exhibited reductions in stomatal densities which represented $80 \%$ of wild-type densities, whereas stomagen possessed only $25 \%$ of wild-type densities in the fifth fully expanded adult leaf and flag leaf, respectively (Fig. 2d-e). Stomatal size was measured to determine if there was a relationship between stomatal density reductions and size increases in the Nipponbare background. Consistent with previous reports, the guard cell length of stomata in stomagen were longer relative to epfl10 and wild type (Fig. 2f) (Caine et al., 2019; Mohammed et al., 2019).

\section{Stomatal conductance, carbon assimilation, and stomatal aperture}

Infrared gas exchange analysis of reduced density lines was undertaken to determine if lines with conductance $\left(\mathrm{g}_{\mathrm{s}}, \mathrm{mol} \mathrm{H}_{2} \mathrm{O} \mathrm{m}^{-2} \mathrm{~s}^{-1}\right)$. At ambient $\mathrm{CO}_{2}(400 \mathrm{ppm})$ and saturating light $(1000 \mu \mathrm{mol}$ photons $\left.\mathrm{m}^{-2} \mathrm{~s}^{-1}\right)$, stomagen steady-state $\mathrm{A}_{\mathrm{n}}$ and $\mathrm{g}_{\mathrm{s}}$ were lower relative to the wild type grown in growth chambers (Fig. 3a,c). Interestingly, wild type and epfllo displayed similar steady-state values (Fig. 3a-d). Likewise, epfl10 maintained wild type levels of $A_{n}$ and $g_{s}$ whereas stomagen did not in light response curves carried out on an independent cohort of plants in the greenhouse 
(Fig. 3b,d). Similar reductions of $\mathrm{A}_{\mathrm{n}}$ and $\mathrm{g}_{\mathrm{s}}$ in stomagen lines were recapitulated in greenhouse measurements at $1000 \mu \mathrm{mol}$ photons $\mathrm{m}^{-2} \mathrm{~s}^{-1}$ (Fig. S1). However, stomagen did not exhibit lowered levels of carbon assimilation at $1000 \mu \mathrm{mol}$ photons $\mathrm{m}^{-2} \mathrm{~s}^{-1}$ after vegetative drought stress despite still having reduced levels of stomatal conductance (Fig. S1c-d). Measurements of stomatal apertures on the abaxial side of flag leaves indicated that epfllo lines maintained a larger stomatal aperture than the wild type, and stomagen lines exhibited an even greater aperture (Fig. 3e). Thus, epfl10 and stomagen maintained even greater levels of stomatal conductance per individual stoma mediated by a larger aperture (Fig. 3f).

\section{Leaf temperature and water conservation}

Thermal imaging was used to assess evaporative cooling in altered stomatal lines. In wellwatered conditions stomagen lines were warmer on average than wild type, whereas epfl10 leaf temperatures were intermediate (Fig. 4a). No difference in leaf temperature was detected during vegetative drought (Fig. 4b). During reproductive drought, eplf10 was marginally cooler than stomagen (Fig. 4c). To test the impact of reduced stomatal densities on water conservation, daily water loss was measured over the course of a week beginning with 70 days after germination. Stomagen and epfl10 both conserved greater volumes of water in a week by $48 \mathrm{~mL}$ and $83 \mathrm{~mL}$, respectively (Fig. 4d).

\section{Yield Trials}

To assess the impacts of stomatal modifications on crop performance, yield trials were conducted using three watering regimes in the greenhouse. In well-watered, vegetative drought, and reproductive drought conditions, there was no discernible difference in grain or biomass yield among genotypes (Fig. S2).

\section{Discussion:}

In current climate conditions, drought is the most severe and widespread environmental stressor in South and Southeast Asia ("Climate change - ready rice | International Rice Research Institute," n.d.). Application of gene editing in crops for climate change could serve as a potent mechanism for realizing actual technology transfer to growers (Jenkins, Dobert, Atanassova, \& Pavely, 2021; Karavolias, Horner, Abugu, \& Evanega, 2021). Previous manipulation of epidermal patterning factors generated rice with improved drought tolerance and maintenance of yields in greenhouse conditions, albeit with reductions in $A_{n}$ and $g_{s}$ (Caine et al., 2019; Dunn et al., 2019; Hughes et al., 2017). In this study, novel characterization of the rice epidermal patterning factor EPFL10 in its native system enabled the development of climate change adapted rice in this study. with a reduced affinity thereby limiting its capacity in positive regulation of stomatal development. Substituted residues in EPFL10 relative to STOMAGEN may underlie the 
beginning of the STOMAGEN domain appears to contact both ERL1 and TMM in the complex structure of EPF1, the two substituted amino acids mapped to this region may be important for alternate binding affinity of EPFL10 (Figure 1e). Additional substituted amino acids may also play a role in lowered relative stability of EPFL10 in the TMM/ERL receptor complex. Lower expression levels of EPFL10 relative to STOMAGEN in leaf base and seedling where new stomatal complexes are forming in combination with a peptide-level difference likely account for the modest reductions of stomatal density in EPFL10 knockouts relative to STOMAGEN (Figure 2a, Figure 1). Greater $\mathrm{CHG}$ and $\mathrm{CHH}$ repressive methylation marks vicinal to the EPFL10 gene relative to STOMAGEN may account for differences in expression and function of these duplicated genes (Figure S3) (Raju, Ledford, \& Niederhuth, 2021). Overall, higher sequence conservation across various species and greater expression levels in relevant tissues signify fundamental roles of STOMAGEN in development. EPFL10 may be selectively utilized to finetune stomatal densities, and relatively divergent sequence evolution may reflect species' adaptations or relaxed purifying selection.

Stomatal density reductions mediated by single gene knockouts of EPFL10 and STOMAGEN were equivalently capable of conserving water. Fewer stomata offer fewer sites for water loss to occur. It is noteworthy that stomagen lines conserved water to a similar extent as epfl10 despite having much greater reductions in stomatal density. Our data indicates that fewer stomata with larger apertures offer comparable water conservativity properties as lines possessing greater number of stomata with smaller apertures. It is still unclear how more severe and/or fieldrelevant drought stresses may affect water loss and assimilation when specific stomatal conductance is limiting. Yet, stomatal reductions broadly offer water-savings relative to wild type.

417 Despite a promising water conservation phenotype, stomagen lines were unable to maintain 418 wild-type levels of $\mathrm{A}_{\mathrm{n}}$ and $\mathrm{g}_{\mathrm{s}}$ whereas epfl10 maintained levels equivalent to wild type across all light and growth conditions. Stomatal conductance and photosynthesis of stomagen but not epfl10 were lower at all light intensities greater than $1000 \mu \mathrm{mol}$ photons $\mathrm{m}^{-2} \mathrm{~s}^{-1}$ relative to wildtype. Fluctuating light in field conditions tends to be present at photosynthetic flux densities greater than $1000 \mu \mathrm{mol} \mathrm{m}{ }^{-2} \mathrm{~s}^{-1}$ in mid-canopy for the majority of the day (Slattery, Walker, Weber, \& Ort, 2018). No differences in grain yield were measured among genotypes despite marked differences in steady state $\mathrm{g}_{\mathrm{s}}$ and $\mathrm{A}_{\mathrm{n}}$ of stomagen lines. A previous greenhouse study in which $g_{s}$ and $A_{n}$ were lowered by EPF1 overexpression did not result in lowered yields (Caine et al., 2019). However, most other literature suggests that high levels of leaf photosynthesis and stomatal conductance are directly linked to higher yields (Kusumi et al., 2017; Ohsumi et al., 2007a; Richards, 2000; Roche, 2015; Taylaran et al., 2011; Zhang et al., 2021). Additional studies of yield in dynamic and substantially more stressful field conditions are thus necessary to reconcile discrepancies with previous reports and more robustly assay the impacts of stomatal density reductions on yield.

Larger stomatal apertures were measured in stomagen and epfl10 lines relative to wild type (Figure 3e). Pore area adjustments in stomagen lines were unable to physiologically compensate for large reductions in stomatal densities, unlike epfl10 lines, which maintained wild-type levels of $A_{n}$ and $g_{s}$ (Figure 3a-d). The theoretical maximum stomatal conductance of grass stomata greatly exceeds the measured stomatal conductance (Caine et al., 2019; Faralli, Matthews, \& 
Lawson, 2019). epfl10 maintained high levels of specific stomatal conductance concurrent with overall $A_{n}$ and $g_{s}($ Figure 3f, Figure 3a-3d, Figure 4d). Enhancing specific stomatal conductance in a reduced density background may thus provide a promising mechanism for maintaining photosynthetic capacities simultaneous with water-use efficiency (C. R. Buckley, Caine, \& Gray, 2019; Faralli et al., 2019).

442 In accordance with anticipated global warming caused by climate change, maintained or 443 improved thermoregulation will be vital for crop agronomic performance (Jagadish et al., 2015). epfl10 maintained wild-type thermoregulation in all watering regimes whereas stomagen lines were warmer in well-watered and reproductive drought conditions (Figure 4a, 4c). A previous report indicated a similar trend wherein lines with reductions in stomatal densities were able to remain cooler during both vegetative and reproductive droughts (Caine et al., 2019). Greater water retention prior to drought may facilitate enhanced thermoregulatory capacities during reproductive drought despite having fewer stomata.

450 Characterization of developmental genes in crop plants can expand upon available developmental frameworks and provide tools for developing the next generation of crops (Hughes et al., 2017; Raissig et al., 2017). The genetics underlying the novel components of grass stomatal development can only be fully resolved by expanding developmental genetics explorations beyond the paradigm of $A$. thaliana investigations. In this case, explorations of the role of EPFL10 unraveled its native function as a weak positive regulator of stomatal development in rice plants. We report here the demonstration of stomatal density reductions with no concomitant reductions in stomatal conductance or carbon assimilation. epfl10 lines maintained wild-type physiological capacities of stomatal conductance, carbon assimilation, thermoregulation, and yield while also conserving more water than wild-type. These attributes could contribute to improved climate resilience in current and future conditions where water is limiting, and temperatures are increased. Field-based investigations of epfl10 and stomagen will further resolve the agronomic utility of these edited rice lines.

\section{Author Contributions:}

NGK developed project idea and coordinated research efforts. NGK constructed gene-editing vectors with assistance from DD. MT and JT with oversight from MJC produced epfl10 and stomagen lines, respectively. KS generated dendrogram, gene tree and peptide models. NGK phenotyped stomatal densities, stomatal aperture, stomatal size, water loss, and yield. GAG repeated stomatal density phenotyping independently to confirm results. NGK and DP conducted gs and A assays. DP captured thermal images. NGK drafted the manuscript with edits from DP and KKN. KKN provided LICOR equipment, thermal imaging equipment, and technical expertise. BJS provided feedback on experimental design and the manuscript as well as the facilities to carry out experiments.

474 Funding statement: Funding provided by Open Philanthropy, Foundation for Food and

475 Agriculture Research, Innovative Genomics Institute and the National Science Foundation 
bioRxiv preprint doi: https://doi.org/10.1101/2021.12.21.473329; this version posted December 23, 2021. The copyright holder for this preprint

(which was not certified by peer review) is the author/funder, who has granted bioRxiv a license to display the preprint in perpetuity. It is made available under aCC-BY-NC-ND 4.0 International license.

476 Graduate Research Fellowship Program. KKN is an investigator of the Howard Hughes Medical 477 Institute.

478

479

480

481

482

483

484

485

486

487

488

489

490

491

492

493

494

495

496

497

498

499

500

501

502

503

504

505 
bioRxiv preprint doi: https://doi.org/10.1101/2021.12.21.473329; this version posted December 23, 2021. The copyright holder for this preprint (which was not certified by peer review) is the author/funder, who has granted bioRxiv a license to display the preprint in perpetuity. It is made available under aCC-BY-NC-ND 4.0 International license.

(a)

509

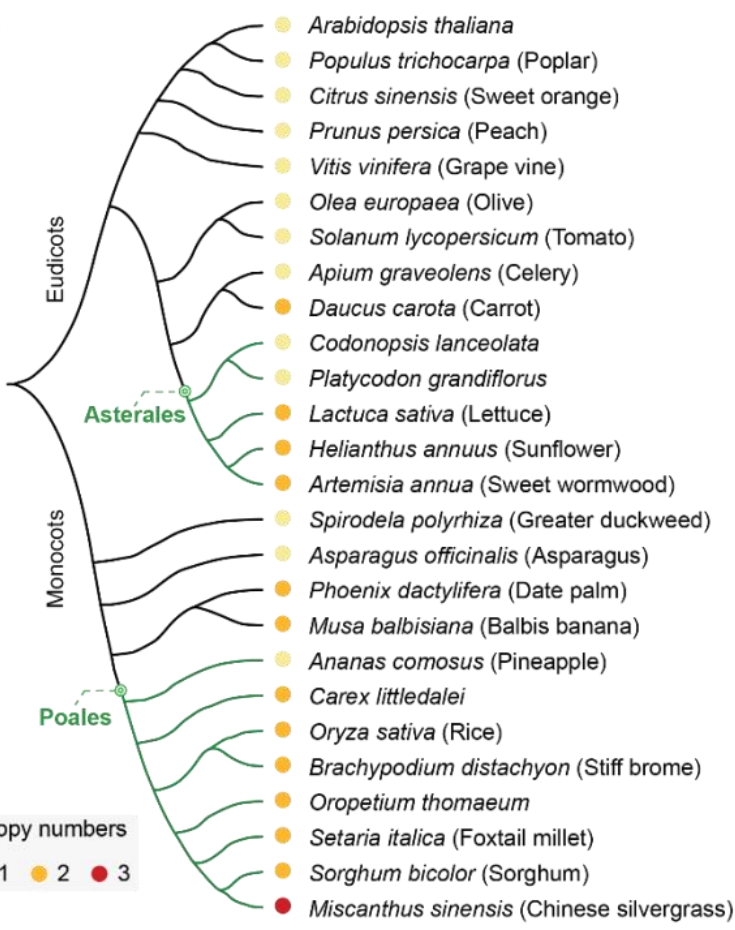

(b)

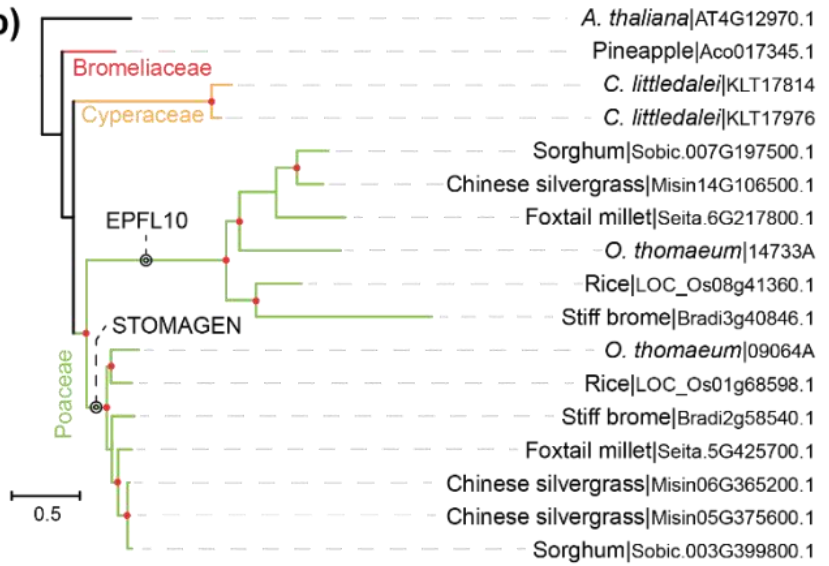

(c)

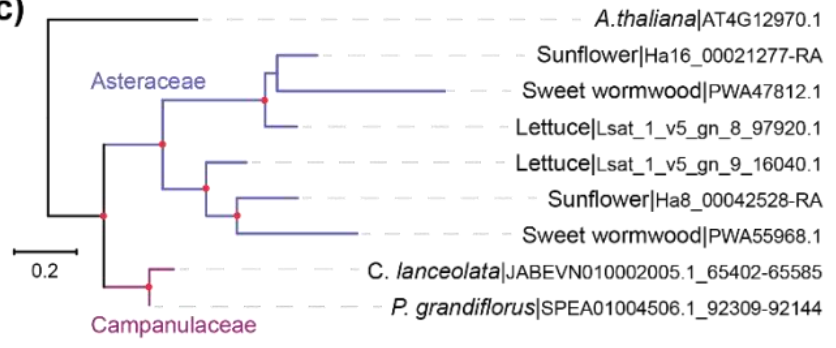

(d) Position (EPFL10)

(e)

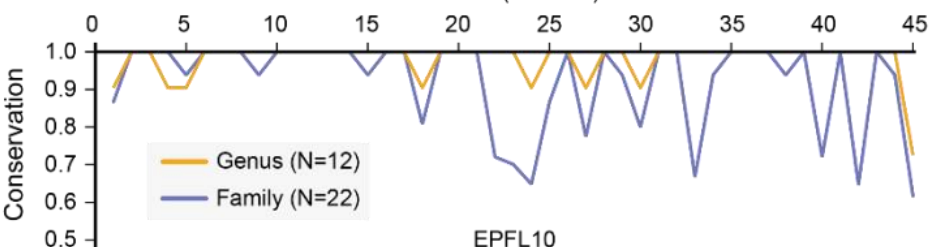

EPFL10

IGSRAPTCTYNECRGCRRRCSVQEVPVDAGD PMNSAYHYRCICHI IGSTAPICTYNECRGCRFKCTAEQVPVDANDPMNSAYHYKCVCHR
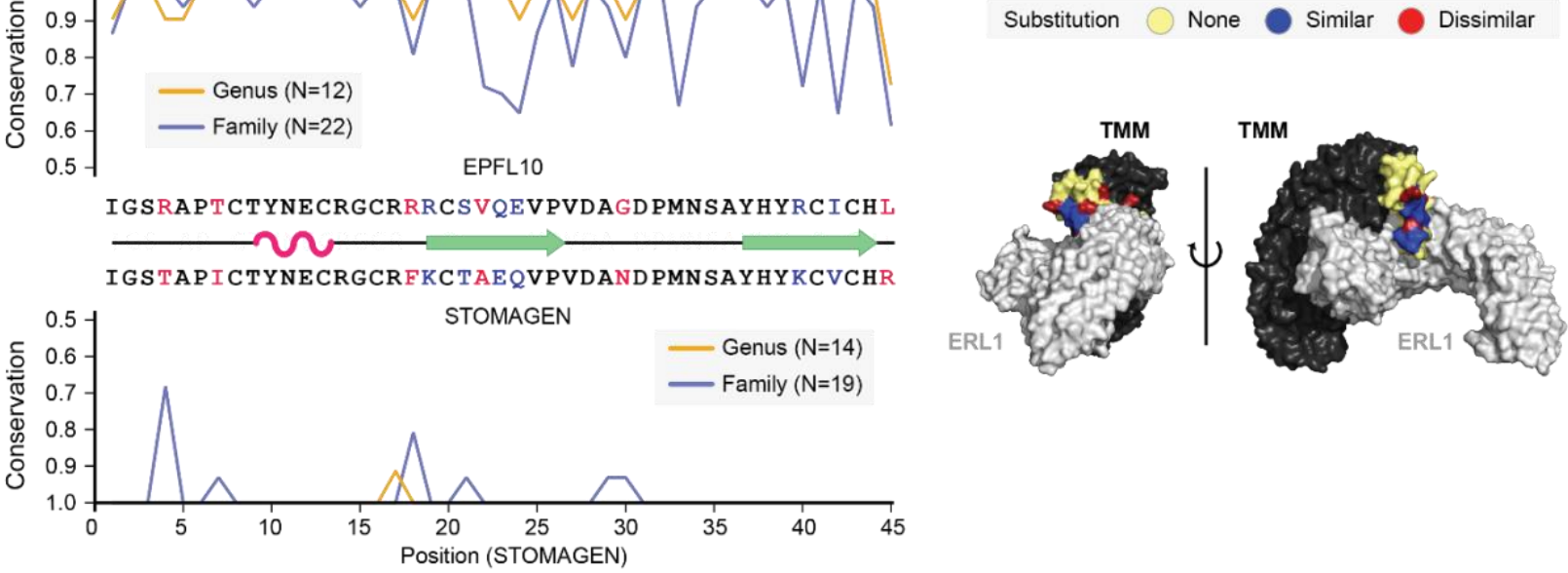
bioRxiv preprint doi: https://doi.org/10.1101/2021.12.21.473329; this version posted December 23, 2021. The copyright holder for this preprint (which was not certified by peer review) is the author/funder, who has granted bioRxiv a license to display the preprint in perpetuity. It is made available under aCC-BY-NC-ND 4.0 International license.

\section{Figure 2}

(a)

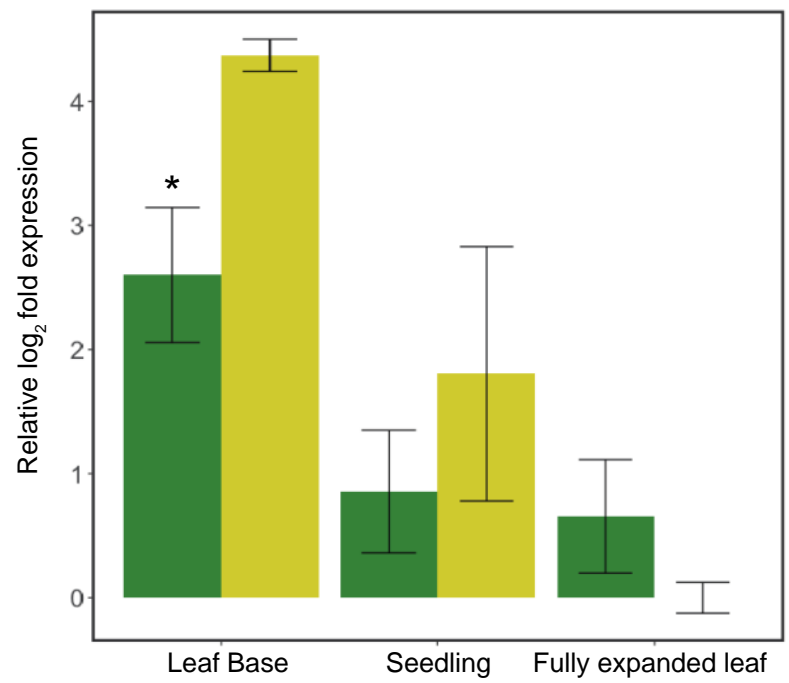

(b)

\section{STOMAGEN}

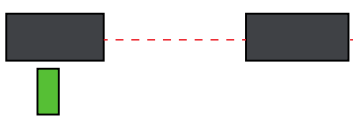

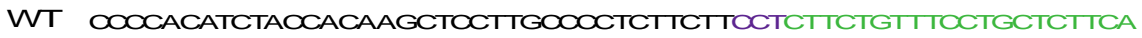

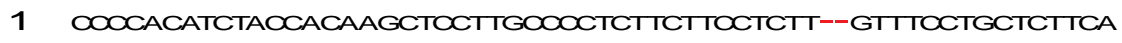

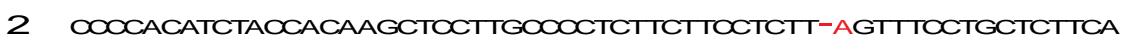

(c)

EPFL10
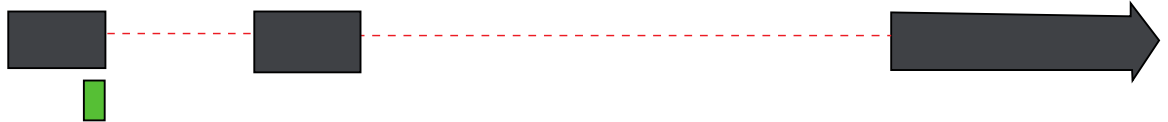

WT TGAAGATGTTGCTGTACTTTCTTCTOCTGATOGTTGOCACTCTTGTGATTACTGCAGG

1 TGAAGATGTTGCTGTACTITCTTCTOCTGATOGTTGOCACTCTTGTGATTA- TGCAGG

2 TGAAGATGTTGCTGTACTITCTTCTOCTGATOGTTGOCACTCTTGTGATTACATGCAGG

(d)

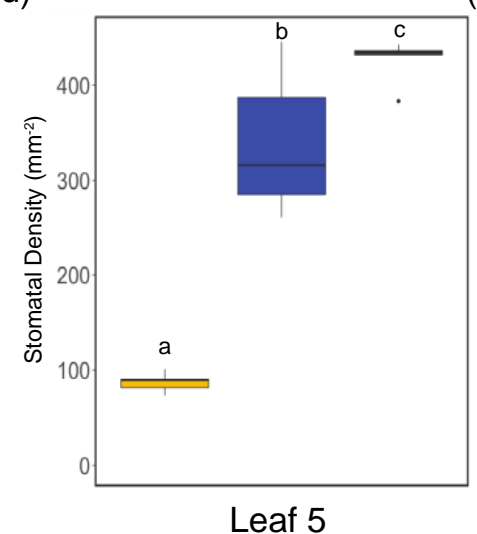

(e)

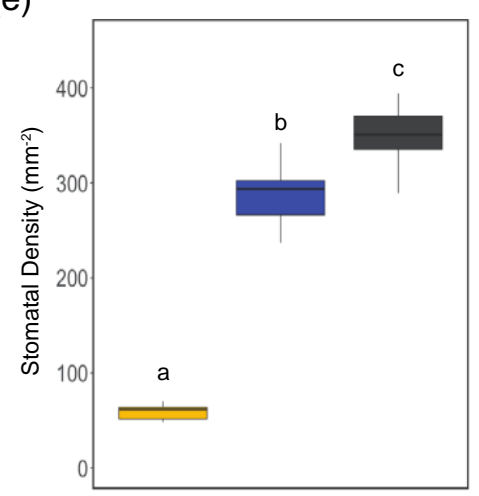

Flag Leaf (f)

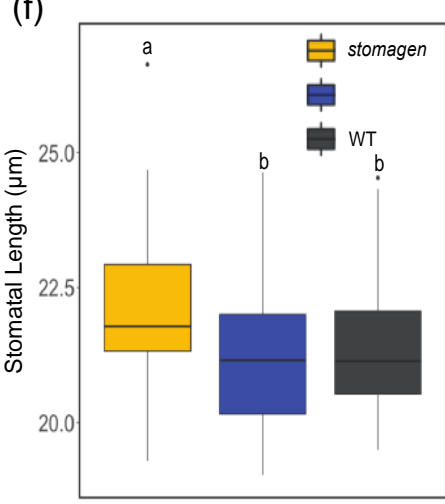


556

557

558

559

560

561

562

563

564

565

566

567

568

569

570

571

572

573

574

575

576

577

578

579

580

581

582

583

584

585

586

587

588

589

590

591

592

593

594

595

596

597

598

599

600

601

\section{Figure 3}

(a)

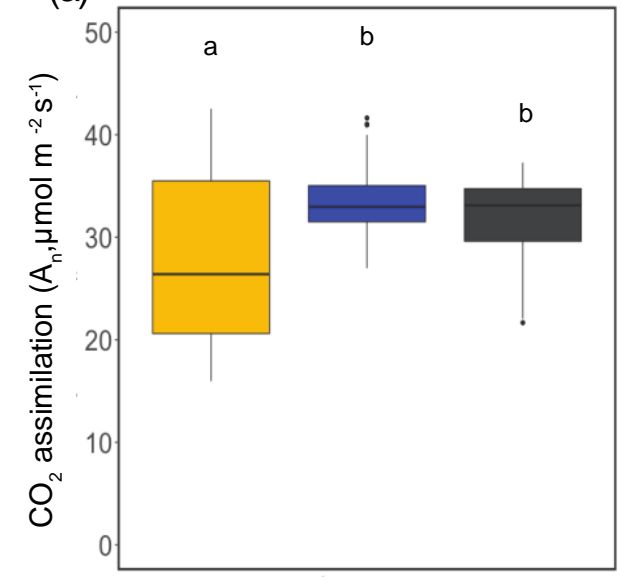

(c)

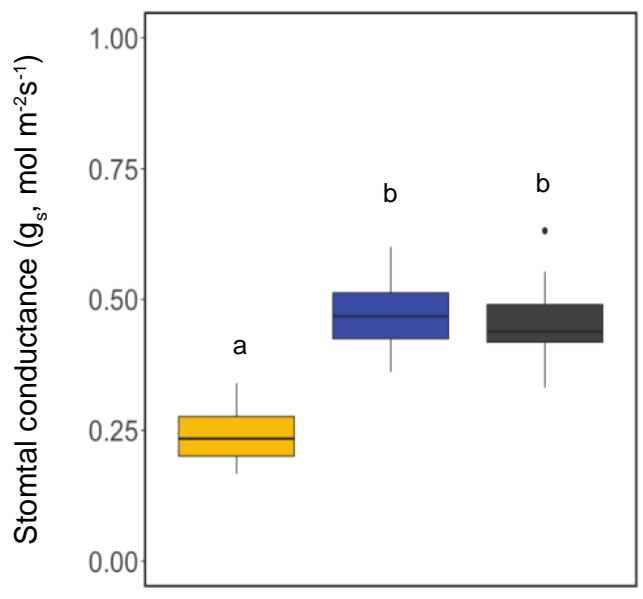

(e)
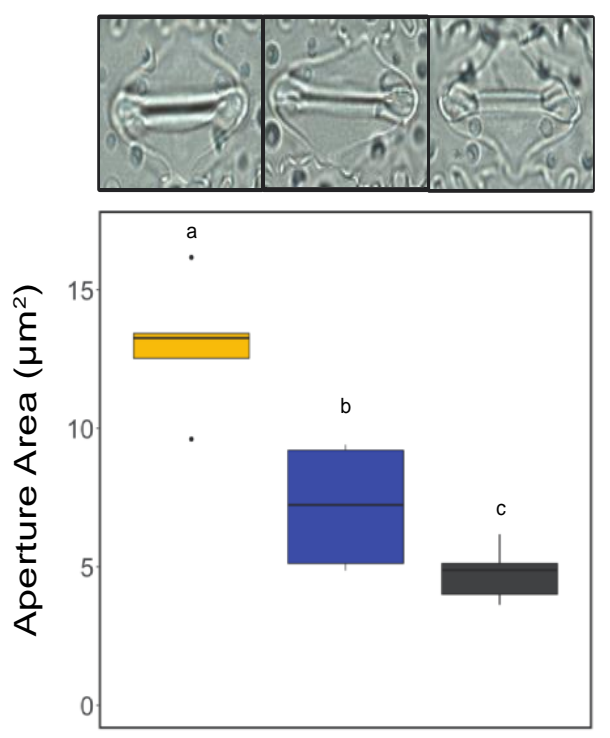

(b)

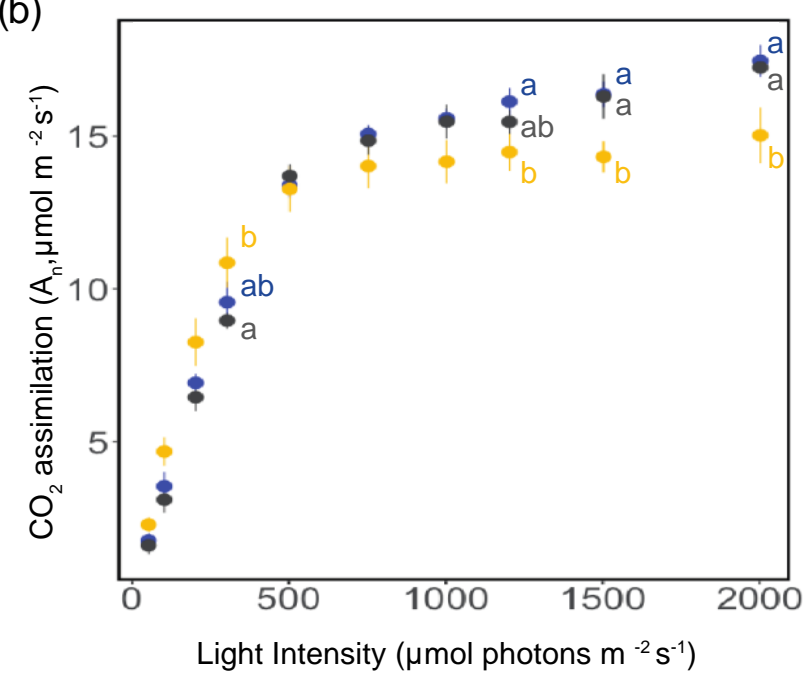

(d)

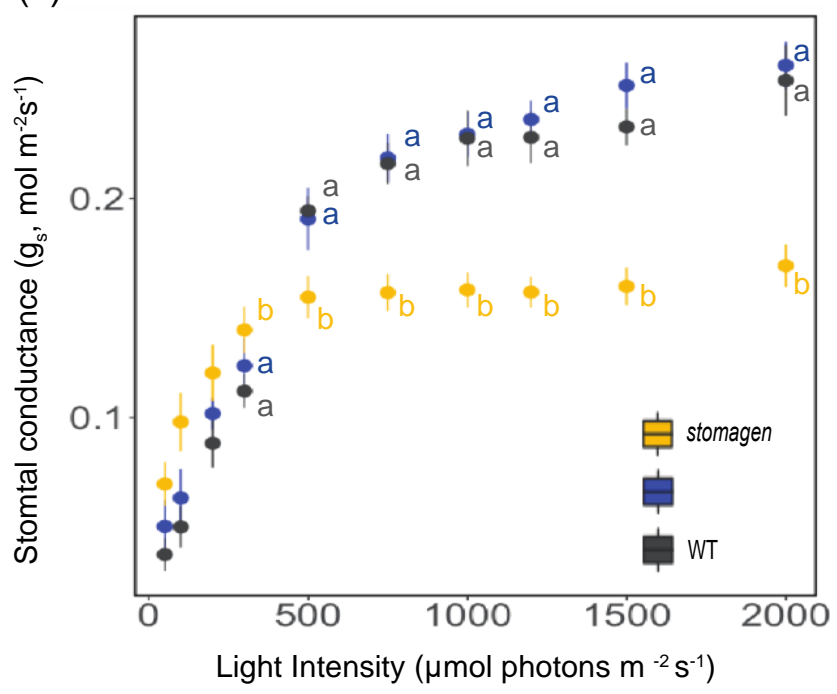

(f)

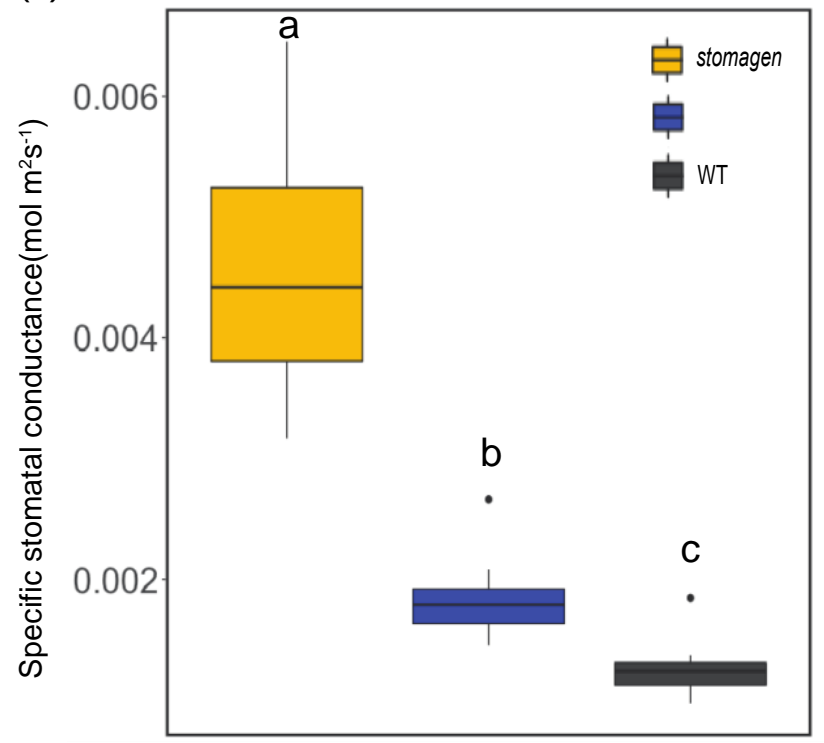


bioRxiv preprint doi: https://doi.org/10.1101/2021.12.21.473329; this version posted December 23, 2021. The copyright holder for this preprint (which was not certified by peer review) is the author/funder, who has granted bioRxiv a license to display the preprint in perpetuity. It is made available under aCC-BY-NC-ND 4.0 International license.

602

603

604

605

606

607

608

609

610

611

612

613

614

615

616

617

618

619

620

621

622

623

624

625

626

627

628

629

630

631

632

633

634

635

636

637

638

639

640

641

642

643

644

645

646

647
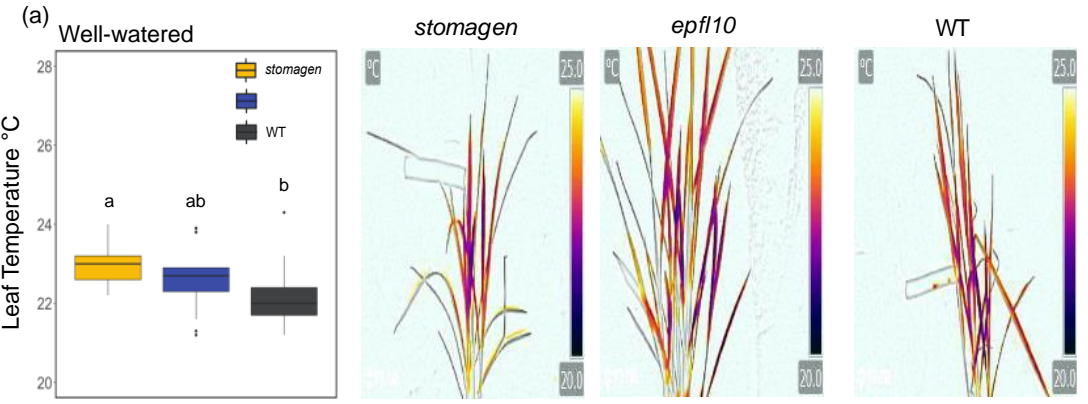

(b)

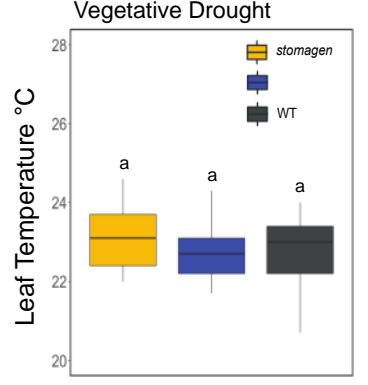

stomagen

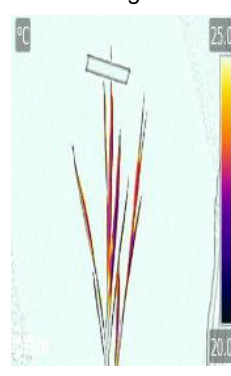

epfl10

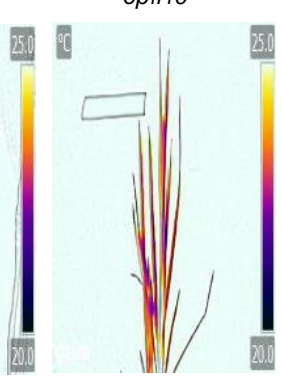

WT
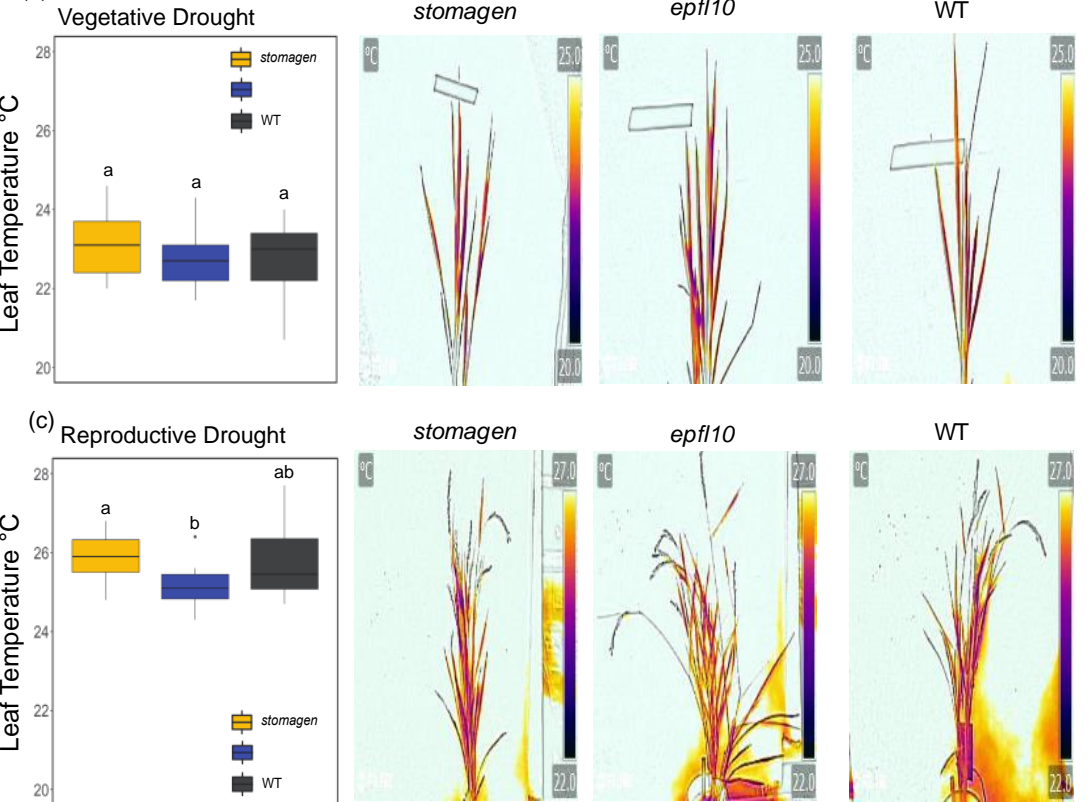

stomagen
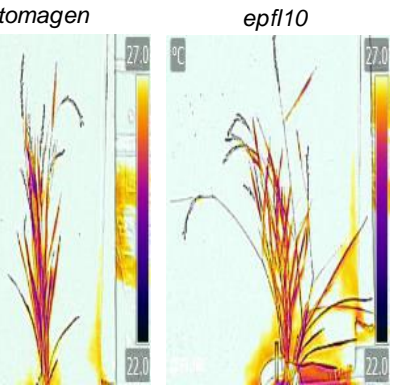

WT

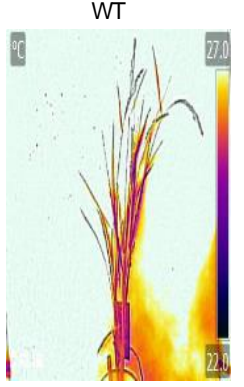

(d)

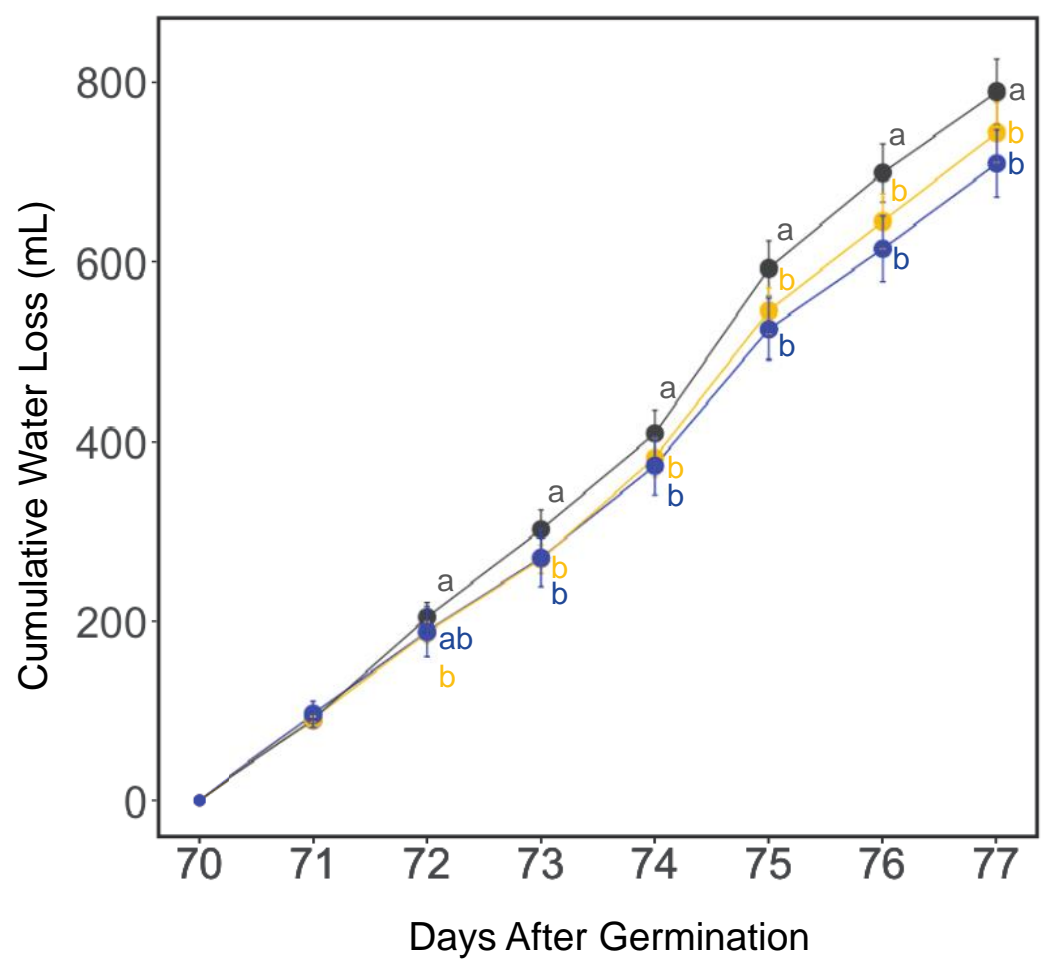


Figure 1. The evolution of STOMAGEN and EPFL10 (a) A dendrogram of angiosperm species and copy number variations of STOMAGEN family members. (b-c) Gene trees of the STOMAGEN family members in Poales and Asterales, respectively. Arabidopsis was used as an outgroup. (d) Genus and family-level sequence conservation of STOMAGEN and EPFL10 orthologs. The sequence conservation is calculated by 1 - normalized Shannon's entropy, with 1 being perfect conservation and 0 being completely variable. The secondary structure annotation originates from the solved structure of STOMAGEN (PDB: 2LIY) (Ohki et al., 2011). The colored residues highlight variable positions between rice STOMAGEN and EPFL10. Substitutions to similar and dissimilar amino acids based on BLOSUM62 are indicated with blue and red. (e) The variable positions between STOMAGEN and EPFL10 mapped to the solved complex structure of EPF1, ERL1 and TMM (PDB: 5XJO)(Lin et al., 2017). The variable positions with similar or dissimilar substitutions follow (d).

Figure 2. EPFL10 is a weak positive regulator of stomatal development in Nipponbare (Oryza sativa spp. Japonica). (a) qRT-PCR determined expression levels of EPFL10 and STOMAGEN in fully expanded leaf, leaf base, and seedling. Bars represent means and error bars represent standard deviation from the mean. The asterisk indicates a significant difference between the means (P<0.05). (b,c) Representative gene models of STOMAGEN (b) and EPFL10 (c) with guide sequence in green and PAM sequence in blue. Homozygous edits generated in two mutant lines by CRISPR/Cas9 are shown in red. (d,e) Stomatal density of epfl10, stomagen, and wild type. d.) Stomatal density of the fifth fully expanded true leaf. Stomatal densities of 21-day old plants were measured e.) Stomatal density of the flag leaf on the primary tiller during grain filling. Flag leaves of 55-day old plants were measured. (f) Stomatal length of epfl10, stomagen, and wild type. Graphs D-F are box-and-whisker plots where the center horizontal indicates the median, upper and lower edges of the box are the upper and lower quartiles and whiskers extend to the maximum and minimum values within 1.5 interquartile ranges. Outliers are represented by black dots. Letters indicate a significant difference between means $(\mathrm{P}<0.05$, one-way ANOVA Duncan post-hoc test). (a) $\mathrm{N}=3,3$, (d,e) $\mathrm{N}=9,9,9$ (f) $\mathrm{N}=35,35,35$.

Figure 3. Gas exchange measurements and stomatal pore area measurements in reduced stomatal density backgrounds in Nipponbare (Oryza sativa spp. Japonica). (a,b) Gas exchange measurements of carbon assimilation rate of stomagen, epfl10, and wild-type at $1000 \mu \mathrm{mol}$ photons $\mathrm{m}^{-2} \mathrm{~s}^{-1}$ in 21-day-old plants grown in growth chamber (a) and 32-day-old plants grown in the greenhouse across a range of light intensities: 2000, 1500, 120, 1000, 750, 500, 300, 200, $100 \mu \mathrm{mol}$ photons $\mathrm{m}^{-2} \mathrm{~s}^{-1}$ (b). (c,d) Gas exchange measurements of stomatal conductance in stomagen, epfl10, and wild-type at $1000 \mathrm{~mol}^{-2} \mathrm{~s}^{-1}$ in 21-day-old plants grown in growth chamber (c) and 32-day-old plants grown in the greenhouse across a range of light intensities 2000, 1500, 120, 1000, 750, 500, 300, 200, $100 \mu \mathrm{mol}$ photons $\mathrm{m}^{-2} \mathrm{~s}^{-1}$ (d). (e) Representative images of stomatal pore size variation from largest to smallest (left to right), top, and pore area measurements of stomagen, epfl10, and wild-type, bottom. (f) Specific stomatal conductance of epfl10 and stomagen lines. Specific conductance values calculated by dividing stomatal conductance by the average stomatal density of the probe area of the respective genotype. In graphs $b, d$, dots represent means and error bars are standard deviation from the mean. Graphs in $\mathrm{a}, \mathrm{c}, \mathrm{e}$, and $\mathrm{f}$ are box-and-whisker plots where the center horizontal indicates the median, upper and lower edges of the box are the upper and lower quartiles and whiskers extend to the 
694 maximum and minimum values within 1.5 interquartile ranges. Outliers are represented by black

695 dots. Letters indicate a significant difference between means $(\mathrm{P}<0.05$, one-way ANOVA Duncan

696 post-hoc test). (a,c) $\mathrm{N}=8,8,8$ (b,d) $\mathrm{N}=6,5,5$ (e) $\mathrm{N}=5,5,6$.

697

698 Figure 4. Stomatal density reductions influence thermoregulation and water conservation in

699 Nipponbare (Oryza sativa spp. Japonica). (a-c) Leaf temperatures of stomagen, epfl10, and wild-

700 type, left, with representative thermal images of each genotype, right. (a) In well-watered, (b) In

701 vegetative drought, and (c) In reproductive drought. (d) Cumulative water loss of stomagen,

702 epfl10, and wild type from days 70-77 after germination. Graphs in A-C are box-and-whisker

703 plots where the center horizontal indicates the median, upper and lower edges of the box are the

704 upper and lower quartiles and whiskers extend to the maximum and minimum values within 1.5

705 interquartile ranges. Outliers are represented by black dots. In graph D dots represent means and

706 error bars are standard error from the mean. Letters indicate a significant difference between

707

708

709

710

711

712

713

714

715

716

717

718

719

720

721

722

723

724

725

726 
Works Cited:

Bairu, M. W., Aremu, A. O., \& Van Staden, J. (2010). Somaclonal variation in plants: causes and detection methods. Plant Growth Regulation 2010 63:2, 63(2), 147-173. https://doi.org/10.1007/S10725-010-9554-X

Bernier, J., Atlin, G. N., Serraj, R., Kumar, A., \& Spaner, D. (2008). Breeding upland rice for drought resistance. Journal of the Science of Food and Agriculture, 88(6), 927-939. https://doi.org/10.1002/JSFA.3153

Buckley, C. R., Caine, R. S., \& Gray, J. E. (2019). Pores for thought: Can genetic manipulation of stomatal density protect future rice yields? Frontiers in Plant Science, 10, 1783. https://doi.org/10.3389/FPLS.2019.01783

Buckley, T. N. (2005). The control of stomata by water balance. New Phytologist, 168(2), 275292. https://doi.org/10.1111/j.1469-8137.2005.01543.x

Caine, R. S., Yin, X., Sloan, J., Harrison, E. L., Mohammed, U., Fulton, T., ... Gray, J. E. (2019). Rice with reduced stomatal density conserves water and has improved drought tolerance under future climate conditions. New Phytologist, 221(1), 371-384. https://doi.org/10.1111/nph.15344

Capella-Gutiérrez, S., Silla-Martínez, J. M., \& Gabaldón, T. (2009). trimAl: A tool for automated alignment trimming in large-scale phylogenetic analyses. Bioinformatics, 25(15). https://doi.org/10.1093/bioinformatics/btp348

Cho, M. J., Yano, H., Okamoto, D., Kim, H. K., Jung, H. R., Newcomb, K., ... Lemaux, P. G. (2004). Stable transformation of rice (Oryza sativa L.) via microprojectile bombardment of highly regenerative, green tissues derived from mature seed. Plant Cell Reports, 22(7). https://doi.org/10.1007/s00299-003-0713-7

Chu, C. C., Want, C. C., Sun, C. S., Hsu, C., Yin, K. C., Chu, C. Y., \& Bi, F. Y. (1975). Establishment of an efficient medium for anther culture of rice, through comparative experiments on the nitrogen sources. Sci Sin, 18.

Climate change - ready rice | International Rice Research Institute. (n.d.). Retrieved December 9, 2021, from https://www.irri.org/climate-change-ready-rice

Dunn, J., Hunt, L., Afsharinafar, M., Meselmani, M. Al, Mitchell, A., Howells, R., ... Gray, J. E. (2019). Reduced stomatal density in bread wheat leads to increased water-use efficiency. Journal of Experimental Botany, 70(18), 4737-4748. https://doi.org/10.1093/JXB/ERZ248

Eddy, S. R. (2011). Accelerated profile HMM searches. PLoS Computational Biology, 7(10). https://doi.org/10.1371/journal.pcbi.1002195

Eisele, J. F., Fäßler, F., Bürgel, P. F., \& Chaban, C. (2016). A Rapid and Simple Method for Microscopy-Based Stomata Analyses. PLOS ONE, 11(10), e0164576. https://doi.org/10.1371/JOURNAL.PONE.0164576

Endo, H., \& Torii, K. U. (2019). Stomatal Development and Perspectives toward Agricultural Improvement. Cold Spring Harbor Perspectives in Biology, 11(5), a034660. https://doi.org/10.1101/cshperspect.a034660

Faralli, M., Matthews, J., \& Lawson, T. (2019). Exploiting natural variation and genetic manipulation of stomatal conductance for crop improvement. Current Opinion in Plant 
Biology. https://doi.org/10.1016/j.pbi.2019.01.003

782

783

784

785

786

787

788

789

790

791

792

793

794

795

796

797

798

799

800

801

802

803

804

805

806

807

808

809

810

811

812

813

814

815

816

817

818

819

820

821

822

Fischer, R. A., Rees, D., Sayre, K. D., Lu, Z. M., Condon, A. G., \& Larque Saavedra, A. (1998). Wheat yield progress associated with higher stomatal conductance and photosynthetic rate, and cooler canopies. Crop Science, 38(6), 1467-1475. https://doi.org/10.2135/cropsci1998.0011183X003800060011x

Food and Agriculture Organisation (FAO). (2020). FAOSTAT: Statistical database.

Franks, P. J., W. Doheny-Adams, T., Britton-Harper, Z. J., \& Gray, J. E. (2015). Increasing water-use efficiency directly through genetic manipulation of stomatal density. New Phytologist, 207(1), 188-195. https://doi.org/10.1111/nph.13347

Hara, K., Kajita, R., Torii, K. U., Bergmann, D. C., \& Kakimoto, T. (2007). The secretory peptide gene EPF1 enforces the stomatal one-cell-spacing rule. https://doi.org/10.1101/gad.1550707

Hara, K., Yokoo, T., Kajita, R., Onishi, T., Yahata, S., Peterson, K. M., ... Kakimoto, T. (2009). Epidermal Cell Density is Autoregulated via a Secretory Peptide, EPIDERMAL PATTERNING FACTOR 2 in Arabidopsis Leaves. Plant and Cell Physiology, 50(6), 1019-1031. https://doi.org/10.1093/PCP/PCP068

Hepworth, C., Caine, R. S., Harrison, E. L., Sloan, J., \& Gray, J. E. (2018). Stomatal development: focusing on the grasses. Current Opinion in Plant Biology, 4l(Stage 5), 1-7. https://doi.org/10.1016/j.pbi.2017.07.009

Hepworth, C., Doheny-Adams, T., Hunt, L., Cameron, D. D., \& Gray, J. E. (2015). Manipulating stomatal density enhances drought tolerance without deleterious effect on nutrient uptake. New Phytologist, 208(2), 336-341. https://doi.org/10.1111/NPH.13598

Huang, L., Chen, L., Wang, L., Yang, Y., Rao, Y., Ren, D., ... Zeng, D. (2019). A Nckassociated protein 1-like protein affects drought sensitivity by its involvement in leaf epidermal development and stomatal closure in rice. The Plant Journal, tpj.14288. https://doi.org/10.1111/tpj.14288

Hughes, J., Hepworth, C., Dutton, C., Dunn, J. A., Hunt, L., Stephens, J., ... Gray, J. E. (2017). Reducing Stomatal Density in Barley Improves Drought Tolerance without Impacting on Yield. Plant Physiology, 174(2), 776-787. https://doi.org/10.1104/pp.16.01844

Hunt, L., Bailey, K. J., \& Gray, J. E. (2010). The signalling peptide EPFL9 is a positive regulator of stomatal development. New Phytologist, 186(3), 609-614. https://doi.org/10.1111/J.1469-8137.2010.03200.X

Hunt, L., \& Gray, J. E. (2009). The Signaling Peptide EPF2 Controls Asymmetric Cell Divisions during Stomatal Development. Current Biology, 19(10), 864-869. https://doi.org/10.1016/J.CUB.2009.03.069

IPCC, Masson-Delmotte, V., Zhai, P., Pirani, A., Connors, S. L., Péan, C., ... B., Z. (2021). Climate Change 2021: The Physical Science Basis. Contribution of Working Group I to the Sixth Assessment Report of the Intergovernmental Panel on Climate Change. Cambridge University Press.

Jagadish, S. V. K., Murty, M. V. R., \& Quick, W. P. (2015). Rice responses to rising temperatures - challenges, perspectives and future directions. Plant, Cell \& Environment, 38(9), 1686-1698. https://doi.org/10.1111/PCE.12430 
Jägermeyr, J., Müller, C., Ruane, A. C., Elliott, J., Balkovic, J., Castillo, O., ... Rosenzweig, C. (2021). Climate impacts on global agriculture emerge earlier in new generation of climate and crop models. Nature Food 2021, 1-13. https://doi.org/10.1038/s43016-021-00400-y

Jain, N., Vergish, S., \& Khurana, J. P. (2018). Validation of house-keeping genes for normalization of gene expression data during diurnal/circadian studies in rice by RT-qPCR. Scientific Reports, 8(1), 3203. https://doi.org/10.1038/S41598-018-21374-1

Jangra, R., Brunetti, S. C., Wang, X., Kaushik, P., Gulick, P. J., Foroud, N. A., ... Lee, J. S. (2021). Duplicated antagonistic EPF peptides optimize grass stomatal initiation. https://doi.org/10.1242/dev.199780

Jenkins, D., Dobert, R., Atanassova, A., \& Pavely, C. (2021). Impacts of the regulatory environment for gene editing on delivering beneficial products. In Vitro Cellular \& Developmental Biology, 1. https://doi.org/10.1007/S11627-021-10201-4

Karavolias, N. G., Horner, W., Abugu, M. N., \& Evanega, S. N. (2021). Application of Gene Editing for Climate Change in Agriculture. Frontiers in Sustainable Food Systems, 0, 296. https://doi.org/10.3389/FSUFS.2021.685801

Katoh, K., \& Standley, D. M. (2013). MAFFT multiple sequence alignment software version 7: Improvements in performance and usability. Molecular Biology and Evolution, 30(4). https://doi.org/10.1093/molbev/mst010

Khush, G. S. (1997). Origin, dispersal, cultivation and variation of rice. Plant Molecular Biology, 35(1-2). https://doi.org/10.1007/978-94-011-5794-0_3

Kusumi, K., Hashimura, A., Yamamoto, Y., Negi, J., \& Iba, K. (2017). Contribution of the Stype anion channel SLAC1 to stomatal control and its dependence on developmental stage in rice. Plant and Cell Physiology, 58(12), 2085-2094. https://doi.org/10.1093/pcp/pcx142

Lafitte, H. R., Ismail, A., \& Bennett, J. (2004). Abiotic stress tolerance in rice for Asia : progress and the future. Crop Science.

Lee, J. S., Hnilova, M., Maes, M., Lin, Y. C. L., Putarjunan, A., Han, S. K., .. Torii, K. U. (2015). Competitive binding of antagonistic peptides fine-tunes stomatal patterning. Nature. https://doi.org/10.1038/nature14561

Lin, G., Zhang, L., Han, Z., Yang, X., Liu, W., Li, E., ... Chai, J. (2017). A receptor-like protein acts as a specificity switch for the regulation of stomatal development. Genes \& Development, 31(9), 927-938. https://doi.org/10.1101/GAD.297580.117

Liu, T., Ohashi-Ito, K., \& Bergmann, D. C. (2009). Orthologs of Arabidopsis thaliana stomatal bHLH genes and regulation of stomatal development in grasses. Development, 136(13), 2265-2276. https://doi.org/10.1242/DEV.032938

Lu, J., He, J., Zhou, X., Zhong, J., Li, J., \& Liang, Y. K. (2019). Homologous genes of epidermal patterning factor regulate stomatal development in rice. Journal of Plant Physiology, 234235(November 2018), 18-27. https://doi.org/10.1016/j.jplph.2019.01.010

Mistry, J., Chuguransky, S., Williams, L., Qureshi, M., Salazar, G. A., Sonnhammer, E. L. L., ... Bateman, A. (2021). Pfam: The protein families database in 2021. Nucleic Acids Research, 49(D1). https://doi.org/10.1093/nar/gkaa913

Mohammed, U., Caine, R. S., Atkinson, J. A., Harrison, E. L., Wells, D., Chater, C. C., ... 
Murchie, E. H. (2019). Rice plants overexpressing OsEPF1 show reduced stomatal density and increased root cortical aerenchyma formation. Scientific Reports, 9(1), 1-13. https://doi.org/10.1038/s41598-019-41922-7

Murashige, T., \& Skoog, F. (1962). A Revised Medium for Rapid Growth and Bio Assays with Tobacco Tissue Cultures. Physiologia Plantarum, 15(3). https://doi.org/10.1111/j.13993054.1962.tb08052.x

Niederhuth, C. E., Bewick, A. J., Ji, L., Alabady, M. S., Kim, K. Do, Li, Q., ... Schmitz, R. J. (2016). Widespread natural variation of DNA methylation within angiosperms. Genome Biology 2016 17:1, 17(1), 1-19. https://doi.org/10.1186/S13059-016-1059-0

Ohki, S., Takeuchi, M., \& Mori, M. (2011). The NMR structure of stomagen reveals the basis of stomatal density regulation by plant peptide hormones. Nature Communications, 2(1), 1-7. https://doi.org/10.1038/ncomms 1520

Ohsumi, A., Kanemura, T., Homma, K., Horie, T., \& Shiraiwa, T. (2007a). Genotypic variation of stomatal conductance in relation to stomatal density and length in rice (Oryza sativa L.). Plant Production Science, 10(3), 322-328. https://doi.org/10.1626/pps.10.322

Ohsumi, A., Kanemura, T., Homma, K., Horie, T., \& Shiraiwa, T. (2007b). Genotypic variation of stomatal conductance in relation to stomatal density and length in rice (Oryza sativa L.). Plant Production Science, 10(3), 322-328. https://doi.org/10.1626/pps.10.322

Pandey, S., Bhandari, H., Ding, S., Prapertchob, P., Sharan, R., Naik, D., ... Sastri, A. (2007). Coping with drought in rice farming in Asia: Insights from a cross-country comparative study. In Agricultural Economics (Vol. 37). https://doi.org/10.1111/j.15740862.2007.00246.x

Papanatsiou, M., Petersen, J., Henderson, L., Wang, Y., Christie, J. M., \& Blatt, M. R. (2019). Optogenetic manipulation of stomatal kinetics improves carbon assimilation, water use, and growth. Science (New York, N.Y.), 363(6434), 1456-1459. https://doi.org/10.1126/science.aaw0046

Price, M. N., Dehal, P. S., \& Arkin, A. P. (2010). FastTree 2 - Approximately MaximumLikelihood Trees for Large Alignments. PLOS ONE, 5(3), e9490. https://doi.org/10.1371/JOURNAL.PONE.0009490

Raissig, M. T., Matos, J. L., Anleu Gil, M. X., Kornfeld, A., Bettadapur, A., Abrash, E., ... Bergmann, D. C. (2017). Mobile MUTE specifies subsidiary cells to build physiologically improved grass stomata. Science (New York, N.Y.), 355(6330), 1215-1218. https://doi.org/10.1126/science.aal3254

Raju, S. K. K., Ledford, S. M., \& Niederhuth, C. E. (2021). DNA methylation signatures of duplicate gene evolution in angiosperms. BioRxiv, 2020.08.31.275362. https://doi.org/10.1101/2020.08.31.275362

Rang, Z. W., Jagadish, S. V. K., Zhou, Q. M., Craufurd, P. Q., \& Heuer, S. (2011). Effect of high temperature and water stress on pollen germination and spikelet fertility in rice.

Environmental and Experimental Botany, 70(1), 58-65. https://doi.org/10.1016/J.ENVEXPBOT.2010.08.009

Richards, R. A. (2000). Selectable traits to increase crop photosynthesis and yield of grain crops. Journal of Experimental Botany, 51(suppl_1), 447-458. 
https://doi.org/10.1093/JEXBOT/51.SUPPL_1.447

907

908

909

910

911

912

913

914

915

916

917

918

919

920

921

922

923

924

925

926

927

928

929

930

931

932

933

934

935

936

937

938

939

940

941

942

943

944

945

946

Roche, D. (2015). Stomatal Conductance Is Essential for Higher Yield Potential of C 3 Crops. Critical Reviews in Plant Sciences, 34(4), 429-453. https://doi.org/10.1080/07352689.2015.1023677

Seppey, M., Manni, M., \& Zdobnov, E. M. (2019). BUSCO: Assessing genome assembly and annotation completeness. In Methods in Molecular Biology (Vol. 1962). https://doi.org/10.1007/978-1-4939-9173-0_14

Shah, F., Huang, J., Cui, K., Nie, L., Shah, T., Chen, C., \& Wang, K. (2011). Impact of hightemperature stress on rice plant and its traits related to tolerance. The Journal of Agricultural Science, 149(5), 545-556. https://doi.org/10.1017/S0021859611000360

Shimada, T., Sugano, S. S., \& Hara-Nishimura, I. (2011). Positive and negative peptide signals control stomatal density. Cellular and Molecular Life Sciences. https://doi.org/10.1007/s00018-011-0685-7

Slater, G. S. C., \& Birney, E. (2005). Automated generation of heuristics for biological sequence comparison. BMC Bioinformatics, 6. https://doi.org/10.1186/1471-2105-6-31

Slattery, R. A., Walker, B. J., Weber, A. P. M., \& Ort, D. R. (2018). The Impacts of Fluctuating Light on Crop Performance. Plant Physiology, 176(2), 990-1003. https://doi.org/10.1104/PP.17.01234

Stebbins, G. L., \& Shah, S. S. (1960). Developmental studies of cell differentiation in the epidermis of monocotyledons. II. Cytological features of stomatal development in the Gramineae. Developmental Biology, 2(6). https://doi.org/10.1016/0012-1606(60)90050-6

Sugano, S. S., Shimada, T., Imai, Y., Okawa, K., Tamai, A., Mori, M., \& Hara-Nishimura, I. (2010a). Stomagen positively regulates stomatal density in Arabidopsis. Nature, 463(7278), 241-244. https://doi.org/10.1038/nature08682

Sugano, S. S., Shimada, T., Imai, Y., Okawa, K., Tamai, A., Mori, M., \& Hara-Nishimura, I. (2010b). Stomagen positively regulates stomatal density in Arabidopsis. Nature, 463(7278), 241-244. https://doi.org/10.1038/nature08682

Taylaran, R. D., Adachi, S., Ookawa, T., Usuda, H., \& Hirasawa, T. (2011). Hydraulic conductance as well as nitrogen accumulation plays a role in the higher rate of leaf photosynthesis of the most productive variety of rice in Japan. Journal of Experimental Botany, 62(11), 4067-4077. https://doi.org/10.1093/JXB/ERR126

Tiago D.G. Nunens, Dan Zhang, and M. T. R. (2019). Form, development and function of grass stomata. https://doi.org/10.1111/tpj.14552

Tuong, T. P., \& Bouman, B. A. M. (2009). Rice production in water-scarce environments. In Water productivity in agriculture: limits and opportunities for improvement. https://doi.org/10.1079/9780851996691.0053

Wang, Y., Noguchi, K., Ono, N., Inoue, S., Terashima, I., \& Kinoshita, T. (2014). Overexpression of plasma membrane H+-ATPase in guard cells promotes light-induced stomatal opening and enhances plant growth. Proceedings of the National Academy of Sciences, 111(1), 533-538. https://doi.org/10.1073/PNAS.1305438111

Wei, F.-J., Kuang, L.-Y., Oung, H.-M., Cheng, S.-Y., Wu, H.-P., Huang, L.-T., .. Hsing, Y.-I. 
C. (2016). Somaclonal variation does not preclude the use of rice transformants for genetic screening. The Plant Journal, 85(5), 648-659. https://doi.org/10.1111/tpj.13132

Wickham, H. (2017). ggplot2 - Elegant Graphics for Data Analysis | Hadley Wickham |

Yin, X., Biswal, A. K., Dionora, J., Perdigon, K. M., Balahadia, C. P., Mazumdar, S., ... uptake and photosynthesis. Nature Communications, 12(1), 1-12. 